\title{
Design of 4G Antenna for Mobile Handset
}

\author{
Tejashree S.Sale \\ M.tech Student, Electronics Technology \\ Department of Technology Shivaji University, \\ Kolhapur
}

\author{
U.L.Bombale, Ph.D \\ Professor \\ Department of Technology Shivaji University, \\ Kolhapur
}

\begin{abstract}
A compact multiband planar antenna is designed for mobile phone applications in this paper. A planar monopole antenna into distributed radiating elements has designed to obtain good antenna performance. The proposed antenna is combined of a chopped circular radiator with a meander line and an L-strip coupled element which is an extension of the ground plane. A chopped circular patch and L-shaped coupling strip generates lower band and separate radiator and meander lines generates upper band. A planar structure has dimensions as $17.6 \times 56 \mathrm{~mm}$. Such a planar structure has printed on circuit board. Antenna covers wireless communication bands as LTE 750, GSM 850, GSM 900, DCS 1700, UMTS-2110, and UWB 3100. The designed antenna performance has checked with the help of IE3D simulation software. The proposed antenna has designed and tested practically.
\end{abstract}

\section{General Terms}

Microstrip patch antenna, Mobile communication, Multiband antenna.

\section{Keywords}

Multiband planar Antenna, meander line,communication bands, mobile phone.

\section{INTRODUCTION}

Mobile communication is one of the hottest current areas and is developing extremely fast in present times also led to the advancement of antenna systems in the recent decade. It is rapidly evolved from analog systems to the systems which are capable of multimedia transmission. Besides the attractive appearances of these mobile phones, it must also be small in dimension or size. In these days, mobile communication requires a mobile handset which is to be operated in various communication services with multiple functions. This has been created a great demand for designing multiband antennas and this two things that is small size and multiband antennas making a bit more challenging task for antenna designers to achieve such limitations.

Designing a Multiband antenna,following current trends used in devices that are: slot-type antennas, monopole antennas and planar inverted-F antennas (PIFA) [3], [4]. The planar monopole has a capability to provide a wide impedance bandwidth. A planar multiband antenna is proposed for mobile communication \& ultra wideband applications. The antenna performance is achieved by a planar monopole antenna with multi-resonating elements. The multiband antenna covers all cellular and internet communication bands: LTE 750, GSM 850 (824-960 MHz), GSM 900 (880-960 MHz), DCS (1710-1880 MHz), UMTS-2110 (2110-2200 $\mathrm{MHz}), 2.4 \mathrm{GHz}$ WLAN (2400-2480 MHz), ISM/Bluetooth (2400-2480 MHz), WiMAX (2500-2690 MHz \& 3400-3600 $\mathrm{MHz}$ ) and Ultra Wideband (3.1-10.6 GHz). This design is fully planar, fairly compact, and utilizes low cost Rogers 4360 substrate material.

\section{DESIGN PROCEDURE}

The microstrip patch antenna has been designed by calculating length and width from given equations [3].

$$
\text { Width }=w=\frac{c}{2 f \sqrt{\left(\varepsilon_{r}+1\right) / 2}}
$$

Effective Dielectric constant is calculated from;

$$
\begin{aligned}
& \varepsilon_{\text {reff }}=\frac{\underline{\varepsilon}_{r}+\frac{1}{2}+\underline{\varepsilon}_{r} \frac{-1}{2\left[{ }^{1}\right.}\left[12 \frac{h}{w}\right]^{-\frac{1}{2}}}{2 f \sqrt{\varepsilon}} \\
& L_{\text {eff }}=\frac{c}{\sqrt{\varepsilon}}
\end{aligned}
$$

To calculate length extension ( $\Delta L$ );

$$
\left.\Delta L=0.412 h \mid \frac{\left(\varepsilon_{\text {reff }}+0.3\right)\left(\frac{w}{h}+0.264\right)}{\left(\varepsilon_{\text {reff }}-0.258\right)\left(\frac{w}{h}+0.8\right)}\right)
$$

Length of metallic patch;

$$
\text { Length }=L=L_{\text {eff }}-2 \Delta L
$$

\section{DESIGN AND ANALYSIS OF 4G ANTENNA FOR MOBILE HANDSET}

\subsection{Proposed Design}

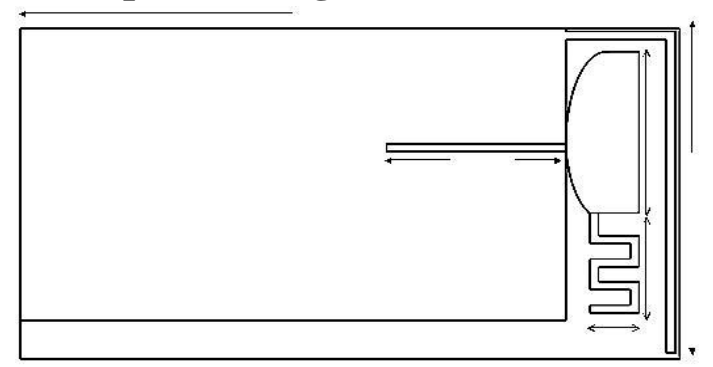

Fig 1: Designed Multi-wideband Antenna 
Then, IE3D Software was chosen to simulate the structure shown in Figure 1.The essential parameters of 4G Antenna are $\mathrm{W}=56 \mathrm{~mm}, \mathrm{~L}=17.6 \mathrm{~mm}$, length of transmission line feed $=$ $15 \mathrm{~mm}$, with width of the feed ( $\mathrm{W} \mathrm{f}$ ) $=3.04 \mathrm{~mm}$.Fig. 1 shows the proposed antenna design. This antenna design is inspired from A Multi-Wideband Planar Monopole Antenna for $4 \mathrm{G}$ Devices by A. Asghar, M. Malick, M. Karlsson and A. Hussain [12].

\subsection{Return loss Characteristics}

A return-loss characteristic of $4 \mathrm{G}$ antenna is shown in figure 2. Return loss is the parameter which indicates the amount of power lost to the load and it does not return as a reflection.

The RL is given as

$$
R L=-20 \log \Gamma|d B|
$$

Return loss should be as small as possible. A value of $-10 \mathrm{db}$ is accepted for better performance. It means that $10 \%$ of total power has been reflected and $90 \%$ of power been transmitted.

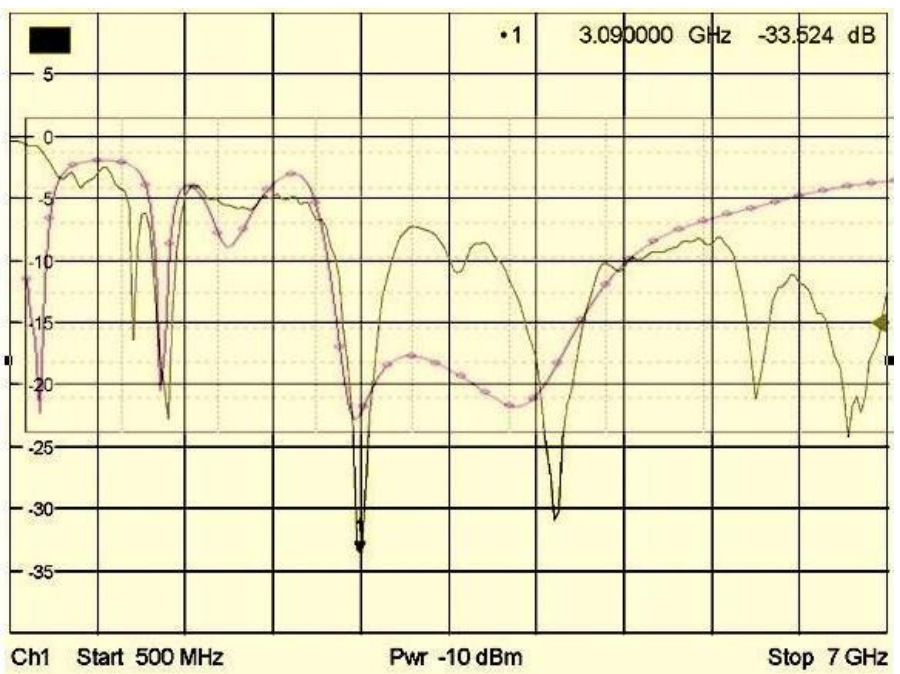

Date: 24.JuN.2014 16:52:52

Measured return loss

Simulated return loss

Fig.2: Return Loss Characteristics of simulated and measured 4G antenna.

\section{RADIATION PATTERN}

a. The measured normalized co-polarized radiation pattern of $4 \mathrm{G}$ antenna in $\mathrm{XZ}$ plane and $\mathrm{YZ}$ plane for $1.69 \mathrm{GHz}$ and $3.09 \mathrm{GHz}$ are shown in fig. 3 and fig. 4 .

The measured normalized co-polarized radiation pattern of $4 \mathrm{G}$ antenna in $\mathrm{XZ}$ plane for $1.69 \mathrm{GHz}$ is shown in figure 3.

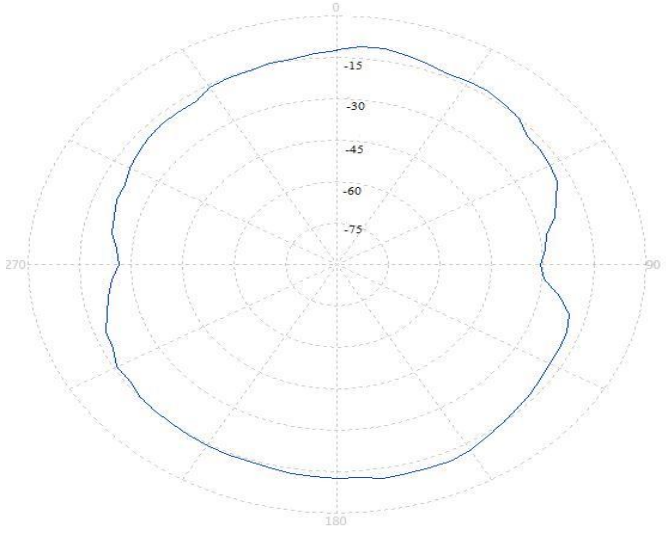

Fig.3: Radiation Pattern of 4G antenna in XZ-plane for 1.69GHz.

The measured normalized co-polarized radiation pattern of 4G antenna in $\mathrm{YZ}$ plane for $1.69 \mathrm{GHz}$ is shown in figure 4.

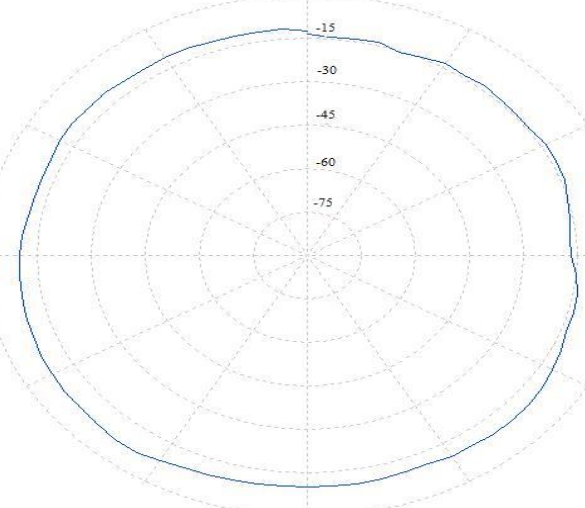

Fig.4: Radiation Pattern of 4G antenna in YZ-plane for $1.69 \mathrm{GHz}$

b. The measured normalized co-polarized radiation pattern of $4 \mathrm{G}$ antenna in $\mathrm{XZ}$ plane and $\mathrm{YZ}$ plane for $3.09 \mathrm{GHz}$ frequency are shown in fig.5 and fig.6.

The measured normalized co-polarized radiation pattern of $4 \mathrm{G}$ antenna in $\mathrm{XZ}$ plane for $3.09 \mathrm{GHz}$ is shown in figure 5 .

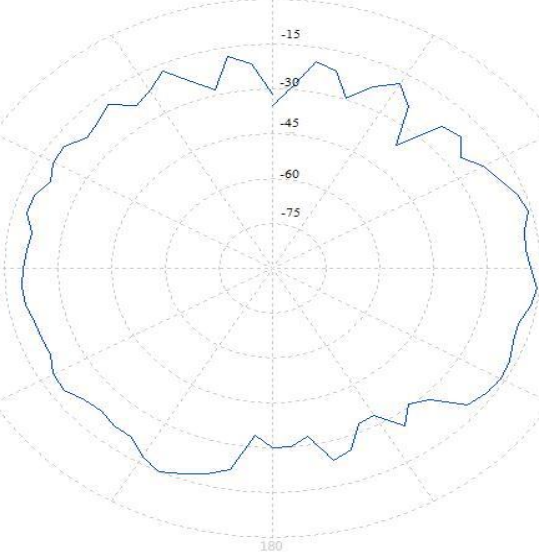

Fig.5: Radiation Pattern of 4G antenna in XZ-plane for 3.09GHz 
The measured normalized co-polarized radiation pattern of $4 \mathrm{G}$ antenna in $\mathrm{YZ}$ plane for $3.09 \mathrm{GHz}$ is shown in figure 6.

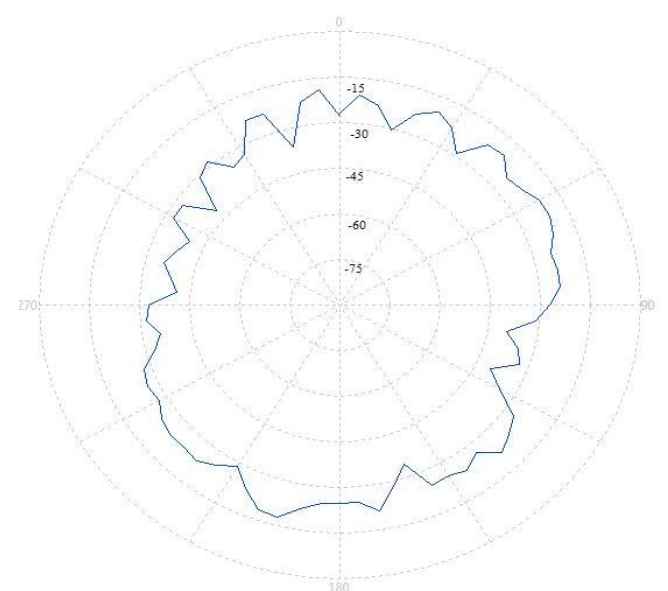

Fig.6: Radiation Pattern of 4G antenna in YZ-plane for 3.09GHz

\section{RESULT AND CONCLUSION}

A 4G antenna has been presented in this article with dimensions $17.6 \times 56 \mathrm{~mm}^{2}$. A planar structure has printed on circuit board. The designed antenna covers wireless communication bands as LTE 750, GSM 850, GSM 900, DCS, UMTS-2110, Bluetooth 2400, WiMAX 2500 and UWB 3100 . The radiation pattern exhibits omnidirectional pattern.

\section{ACKNOWLEDGMENTS}

This research project would not have been possible without the support of my guide, teachers and friends. I am thankful to all the individuals who encouraged and helped me directly and indirectly to carry this work. Their continuous invaluable guidance throughout the course of this study helped me to complete the work.

\section{REFERENCES}

[1] C.A. Balanis. "Antenna Theory: Analysis and Design". 2nd Ed, United States of America, John Wiley \& Sons, 0471592684, 1982.ch. 3 .
[2] Mazinani, S. M. and H. R. Hassani, "A wideband internal plate loaded planar monopole antenna for mobile handset," Journal of Electromagnetic Waves and Applications, Vol. 23, No. 10, 1273-1282, 2009.

[3] Chiu, C. W., C. H. Chang, and Y. J. Chi, "Multiband folded loop antenna for smart phones," Progress In Electromagnetic Research, Vol. 102, 213-226, 2010.

[4] C.W. Chi and C.H. Chang, "Multiband folded loop antenna for smart phones," Progress in Electromagnetic Research Vol. 102, 213-226, 2010.

[5] Cheng, P. C., C. Y. D. Sim, and C. H. Lee, "Multi-band printed internal monopole antenna for mobile handset applications," Journal of Electromagnetic Waves and Applications, Vol. 23, No. 13, 1733-1744, 2009.

[6] Cabedo, A., J. Anguera, C. Picher, M. Ribo, and C. Puente, "Multi-band handset antenna combining a PIFA, slots, and ground plane modes," IEEE Trans. Antennas Propag., Vol. 57, No. 9, 2526-2533, Sep. 2009.

[7] Anguera, J., I. Sanz, J. Mumbru, and C. Puente, "Multiband handset antenna with a parallel excitation of PIFA and slot radiators," IEEE Trans. Antennas Propag., Vol. 58, No. 2, 348-356, Feb. 2010.

[8] Sim, C. Y. D., "Multiband planar antenna design for mobile handset," Microwave Opt. Technol. Lett., Vol. 50, No. 6, 1543-1545, Jun. 2008.

[9] Wong, K.-L., G.-Y. Lee, and T.-W. Chiou, "A lowprofile planar monopole antenna for multiband operation of mobile handsets," IEEE Trans. Antennas Propag., Vol 51, 121-125, Jan. 2003.

[10] Wong, K. L., Y. W. Chi, and S. Y. Tu, "Internal multiband printed folded slot antenna for mobile phone application," Microwave Opt.

[11] Technol. Lett., Vol. 49, No. 8, 1833-1837, Aug. 2007.

[12] A. Asghar, M. Malick, M. Karlsson, Member, IEEE, and A. Hussain 